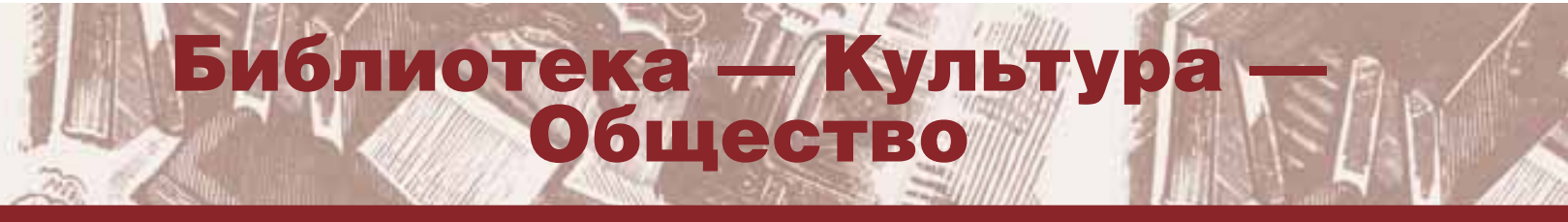

УДК 027.7(100)

ББК 78.347.61(0) + 78.377.5

DOI 10.25281/0869-608X-2020-69-6-567-579

О.Л. ЛАВРИК, Т.А. КАЛЮЖНАЯ

\section{Поддержка научных исследований как направление деятельности библиотек*}

Реферат. Поддержка научных исследований как направление деятельности - одна из ведущих тем, обсуждаемых в библиотечной профессиональной, особенно зарубежной, периодике. В 2020 г. был проведен анализ услуг по поддержке научных исследований, оказываемых научными библиотеками отечественных и зарубежных университетов. Опираясь на опыт исследования 2017 г., для анализа 2020 г. мы разделили все услуги для поддержки научных исследований на две группы: информационно-библиотечные и общенаучные. К информационно-библиотечным услугам отнесены все те, которые библиотека традиционно и с учетом развития современных информационных технологий оказывает своим читателям и пользователям. Общенаучные услуги являются фактически определенным продолжением работы с информацией, но уже полученной исследователями в ходе их работы. Для анализа исследовательских университетов были отобраны российские вузы, попавшие в Шанхайский рейтинг университетов мира за 2020 г. (их оказалось девять), затем - столько же зарубежных университетов.

Сравнение результатов двух исследований показало, что библиотеки университетов нашли устойчивые, необходимые для ученых направления и формы коммуникации. Они могут быть сгруппированы следующим образом: подготовка и ведение специальных ресурсов, априори полезных исследователям для получения информации, необходимой для проведения, продвижения и организации научных

* Исследование выполнено в рамках государственного задания Государственной публичной научнотехнической библиотекой Сибирского отделения Российской академии наук (ГПНТБ СО РАН) (проект № 0334-2019-0001).

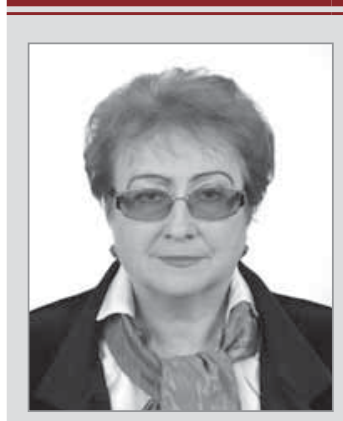

Ольга Львовна Лаврик, Государственная публичная научно-техническая библиотека

Сибирского отделения

Российской академии наук, лаборатория информационносистемного анализа, заведующая, главный научный сотрудник Восход ул., д. 15,

Новосибирск, 630102, Россия доктор педагогических наук, профессор ORCID 0000-0001-8859-8921; SPIN 8304-3655

E-mail: Lavrik@spsl.nsc.ru

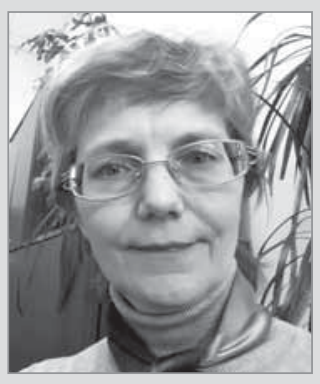

Татьяна Альбертовна

Калюжная,

Государственная публичная научно-техническая

библиотека

Сибирского отделения

Российской академии наук, лаборатория информационносистемного анализа,

старший научный сотрудник

Восход ул., д. 15,

Новосибирск, 630102, Россия кандидат педагогических наук ORCID 0000-0001-8637-2793; SPIN 5315-0638

E-mail: Kalyuzhnaya@spsl.nsc.ru 
исследований; помощь в подготовке публикации; помощь в использовании инструментов для научных коммуникаций; помощь в работе с исследовательскими данными; помощь в работе с наукометрическими данными; комплексная поддержка научных исследований. Это свидетельствует о том, что за четыре года данное направление библиотечно-информационной деятельности в основном сформировано. Единственное существенное различие в деятельности научных библиотек зарубежных и отечественных университетов заключается в том, что последние практически не предлагают услуг по управлению данными. Авторы обращают внимание на появление в библиотечной деятельности такого вида услуги, как помощь на сайтах библиотек отечественных и зарубежных университетов. Предлагается рассмотреть ее в парадигме «помощь - консультирование - сопровождение», отражающей компетентностный уровень библиотекаря.

Ключевые слова: организация библиотечного дела, научные библиотеки, поддержка научных исследований, университеты, направления библиотечно-информационной деятельности, услуги по информационной поддержке научных исследований, услуги по общенаучной поддержке научных исследований.

Для цитирования: Лаврик О.Л., Калюжная Т.А. Поддержка научных исследований как направление деятельности библиотек // Библиотековедение. 2020. Т. 69, № 6. С. 567-579. DOI: 10.25281/0869608X-2020-69-6-567-579.

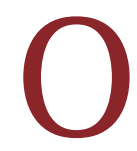
пыт поддержки научных исследований отечественными и, главным образом, зарубежными университетами рассматривался нами ранее. В 2017 г. была опубликована статья [1], целью которой было изучение и обобщение формирующихся направлений работы библиотек университетов для поддержки исследований. Тогда мы пришли к выводу, что в библиотеках вузов идет активный поиск форм работы для развития этого направления, но еще нельзя было назвать устоявшиеся, используемые во всех библиотеках формы (например, в традиционной среде - межбиблиотечный абонемент, выдача книг). Наблюдалась лишь тенденция заниматься всеми аспектами, относящимися к хранению, поиску и использованию полных текстов, метаданных и исследовательских «сырых» данных. Было ощутимо стремление выходить за рамки привычной работы с ресурсами, даже удаленными, и занять нишу, связанную с научно-информационной деятельностью.

Что изменилось за четыре года? В основе нашего обращения к опыту университетских библиотек по-прежнему лежат те же причины. Во-первых, в зарубежных странах наука в основном сосредоточена при университетах, а в России ни один НИИ не может сравниться по численности с профессорско-преподавательским составом крупных университетов, тем более что почти 40\% ученых, работающих в институтах, занимаются преподаванием. Эта проблема осознается и специалистами вузовских библиотек за рубежом, которые с 2010 г. начали ее широкое обсуждение [2; 3], в том числе и на примере конкретных библиотек [4]. По данным на сентябрь 2020 г., в рейтинге РИНЦ - 13930 организаций, и лидеры по числу цитирований - по-прежнему отечественные и зарубежные университеты, а НИИ РАН опустились (по сравнению с 2017 г.) еще ниже, например, Объединенный институт ядерных исследований занимает лишь 27 место. У нас нет данных, чтобы сопоставить число преподавателей в отечественных вузах, являющихся научными сотрудниками институтов, с числом преподавателей, работающих только в вузах и занимающихся научными исследованиями. Во-вторых, библиотека вуза должна быть первой, кто «улавливает» потребности ученых. В-третьих, по текущей публикационной активности вузовские библиотеки опережают библиотеки всех других типов [5]. В-четвертых, в последнее время все больше внимания уделяется предоставлению услуг исследователям, что опять же сказывается на обязанностях университетских библиотекарей и их навыках. Исследовательская информационная сеть (The Research Information Network, RIN) в 2007 г. призвала к новым способам работы в библиотеках для поддержки исследований и определила настоятельную необходимость совместной работы библиотекарей и представителей научного сообщества для уточнения их задач и обязанностей [6]. 
Вопросы обеспечения эффективной и более четкой поддержки научных исследований отражены в большом количестве публикаций, в частности R. Morriello и S. Bains [7; 8] представляют поиск новых форм и методов работы, A. Thomas, E.R. Martin [9] - реальный опыт управления данными. Эта тематика сохраняется в вузах уже более 10 лет и остается весьма актуальной задачей для научных библиотек разного вида: университетов (поддержка научных исследований стала таким же равноправным направлением деятельности, как и поддержка преподавания и обучения), НИИ РАН (всегда занимались информационным обеспечением, сопровождением, а теперь поддержкой научных исследований). Научные коммуникации изменились в принципе, произошли трансформации в организации науки, и появились новые требования к ней. Главное, научные библиотеки перестали быть единственным источником и средством получения научной информации.

Цель статьи - провести сравнительный анализ данных за 2017 и 2020 гг., систематизировать и обобщить данные по услугам, предоставляемым ученым и специалистам библиотеками зарубежных и отечественных университетов для поддержки научных исследований.

\section{Методология, методы и сбор данных}

Выбранные для анализа в 2017 г. университеты и причины выбора описаны в статье «Библиотека и вуз: опыт поддержки научных исследований» [1]. В 2020 г. проведен сбор данных с сайтов с той же целью - понять, как библиотеки исследовательских университетов организуют поддержку научных исследований. Отбор университетов шел по несколько иному принципу. Поскольку нас интересовали именно исследовательские университеты, то был выбран Шанхайский рейтинг как самый приемлемый для ранжирования университетов мира по результатам научных исследований.

Далее следовало определить, какие университеты России считаются исследовательскими ${ }^{1}$. «Национальные исследовательские университеты (НИУ) - это новая категория высших образовательных учреждений России, которая была установлена в отношении двадцати девяти ведущих отечественных университетов с целью создания на их основе передовых научно-образовательных центров мирового класса, обеспечивающих потребности национальной экономики в высококвалифицированных кадрах и способствующих развитию российской науки и технологий» [10]. Московский государственный университет им. M.В. Ломоносова и Санкт-Петербургский государственный университет, которые по умолчанию считаются научными учреждениями, называются научно-образовательными комплексами.

Для анализа отечественных исследовательских университетов из списка НИУ были отобраны российские вузы, попавшие в Шанхайский рейтинг университетов мира за 2020 год. Их оказалось девять, затем из этого рейтинга мы отобрали столько же зарубежных университетов (табл. 1). Среди отечественных НИУ преобладают московские -5 , из СанктПетербурга - 2, по одному - из Новосибирска и Томска; среди зарубежных представлены университеты из США - 7 и Великобритании 2 (старейшие университеты мира). Отметим, что перечни библиотек университетов оказались различны, поскольку нас интересовало развитие не самих библиотек, а услуг по поддержке научных исследований. Поэтому полагаем, что это не повлияло на чистоту результатов исследования, тем более что его объекты (сайты библиотек университетов) частично пересекаются: по зарубежным университетам это Гарвардский, Оксфордский, Кембриджский университеты и Массачусетский технологический институт (4 из 9); по отечественным МГУ им. М.В. Ломоносова, СПбГУ, НГУ, ТГУ, НИЯУ МИФИ и НИУ ВШЭ (6 из 9).

Для сбора и обработки информации применялись следующие методы: структурный и сравнительный анализ, контент-анализ, метод экспертных оценок, формализованные методы. При сборе материала на сайтах отобранных зарубежных университетов изучалось содержание двух разделов - Research и Library.

В ходе мониторинга собирались те же данные:

- путь к услугам для поддержки научных исследований;

- услуги для поддержки научных исследований;

- услуги в группах;

- соотношение информационно-библиотечных и общенаучных услуг для поддержки научных исследований.

Опираясь на опыт предыдущего исследования, для мониторинга 2020 г. мы разделили все услуги для поддержки научных исследований на две группы: информационно-библиотечные и общенаучные (предлагаем обсудить вводимый термин).

К информационно-библиотечным услугам отнесены все те, которые библиотека 


\section{Путь к услугам для поддержки научных исследований (мониторинг 2020 г.)}

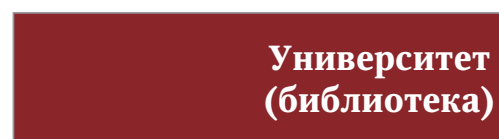

Расположение раздела по поддержке научных исследований на сайте библиотеки ${ }^{\text {a }}$

\section{Отечественные университеты}

Московский государственный университет

(МГУ) им. М.В. Ломоносова

Санкт-Петербургский государственный университет (СПбГУ)

Московский физико-технический институт (МФТИ)

Новосибирский национальный исследовательский государственный университет (НГУ)

Национальный исследовательский ядерный университет «МИФИ» (НИЯУ МИФИ)

Национальный исследовательский университет «Высшая школа экономики» (НИУ ВШЭ)

Национальный исследовательский Томский государственный университет (ТГУ)

Санкт-Петербургский национальный исследовательский университет информационных технологий, механики и оптики (НИУ ИТМО)

Национальный исследовательский технологический университет «МИСиС» (НИТУ «МИСиС»)

\section{Зарубежные университеты}

Гарвардский университет

Стэнфордский университет

Кембриджский университет

Массачусетский технологический институт

Калифорнийский университет

Принстонский университет

Колумбийский университет

Калифорнийский технологический институт

Оксфордский университет research support => Open access $=>$ Research support Research and learning
На титульной странице - разделы «Исследователям», «Авторам»

На титульной странице - раздел «Преподавателю» => «В помощь научной работе»

На титульной странице - раздел «Преподавателям» => «Поддержка публикационной активности»

На титульной странице - раздел «Исследователям и преподавателям»

На титульной странице - раздел «Авторам»

На титульной странице - раздел Staff $=>$ Libraries $=>$ Online

На титульной странице - раздел Research $=>$ Libraries

На титульной странице - раздел Research $=>$ About research

На титульной странице в строке поиска набираем Libraries

На титульной странице - Libraries $=>$ Research support

На титульной странице - Library $=>$ Research tools

На титульной странице - Libraries $=>$ Use the libraries online $=>$ Research \& Learning Support Services

На титульной странице в меню Research $=>$ Research

Facilities $=>$ More than $6000000 \ldots$ at Huntington Library $=>$

На титульной странице - Research, в меню - Libraries => Finding resources. Oxford LibGuied

a Прочерк означает отсутствие данных. 


\section{Соотношение информационно-библиотечных и общенаучных услуг для поддержки научных исследований в отечественных и зарубежных университетах}

Университет (библиотека)

\section{Услуги $^{\text {a }}$}

Информационно-библиотечные

Общенаучные

\section{Отечественные университеты}

\begin{tabular}{|l|c|c}
\hline МГУ им. М.В. Ломоносова & - & - \\
\hline СПбГУ & + & + \\
\hline МФТИ & - & - \\
\hline НГУ & + & + (очень мало) \\
\hline НИЯУ МИФИ & + & + \\
\hline НИУ ВШЭ & - & + \\
\hline ТГУ & + & + \\
\hline НИУ ИТМО & + & В разделе \\
\hline МИСиС & - & $\begin{array}{c}\text { «Электронные ресурсы» } \\
\text { есть ссылки на Scopus и WoS }\end{array}$
\end{tabular}

\section{Зарубежные университеты}

Гарвардский университет

Стэнфордский университет

Кембриджский университет

Массачусетский технологический институт

Калифорнийский университет

Принстонский университет

Колумбийский университет

Калифорнийский технологический институт

Оксфордский университет

\begin{tabular}{|c|c|}
\hline+ & + \\
\hline+ & + \\
\hline+ & + \\
\hline+ & + \\
\hline+ & + \\
\hline+ & + \\
\hline+ & + \\
\hline+ & + \\
\hline+ & $\begin{array}{c}\text { Оказываются, } \\
\text { но преимущественно } \\
\text { не библиотекой }\end{array}$ \\
\hline
\end{tabular}

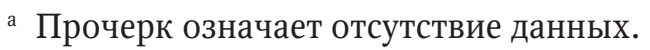

традиционно и с учетом развития современных информационных технологий оказывает своим читателям и пользователям. Общенаучные услуги являются фактически определенным продолжением работы с информацией, но уже полученной исследователями в ходе

их работы. Отсюда вытекают все аспекты, связанные с опубликованием результатов, их продвижением, хранением и обработкой (в целом управление) исходных данных, наукометрическим анализом публикационной активности и т. д. 


\section{Анализ собранных данных}

Сравнительный анализ был опять начат с классического вопроса: как пройти в библиотеку ученому или специалисту с его информационными потребностями? Исходные данные для анализа приведены в таблице 1 .

В отечественных и зарубежных университетах путь к услугам для поддержки научных исследований не изменился. Таким образом, место для них на сайте было определено сразу. Дальнейший анализ привел к следующим результатам.

На сайтах библиотек отечественных университетов:

- не было обнаружено перехода из раздела «Наука» (со страниц университетов) в раздел «Библиотека»;

- о существовании поддержки научных исследований можно говорить применительно лишь к 5 библиотекам из 9;

- библиотеки предоставляют свои ресурсы и услуги чаще всего через раздел «Преподавателям» - 3, «Исследователям» и «Авторам» - по 2 библиотеки;

- общенаучные услуги в основном осуществляются через специально созданные структуры университета. ситетов:

На сайтах библиотек зарубежных универ-

- поддержка научных исследований в 5 университетах из $9-$ в разделе Libraries, у остальных - в Research support, причем на сайтах библиотек в рамках разделов Libraries выделяется Research support, и наоборот, в разделе Research support выделяется Libraries: превалирует поддержка через библиотеки;

- библиотеки выделяют исследователей как специальную группу пользователей, требующую специальных услуг;

- очевидно, что в Оксфорде оказанием общенаучных услуг занимаются не библиотеки, а специально созданные структуры, библиотеки только предоставляют ресурсы.

По результатам мониторинга 2020 г. было проанализировано соотношение оказываемых услуг в отечественных и зарубежных университетах (табл. 2) и их видов (табл. 3,4$)$.

Как видно из таблицы 2, в ряде отечественных университетов информационно-библиотечные услуги хотя и отмечены как имеющиеся, но здесь нет специального повторения информационно-библиотечных услуг для ученых и специалистов. На сайтах библиотек зарубежных университетов, наоборот, как для студентов и профессорско-преподавательского состава, так и для исследователей повторяется практически вся информация по ресурсам, доступу к ним, особенностям поиска и пр.

Сравнение данных 2017 и 2020 гг. показало, что в библиотеках отечественных университетов поддержка научных исследований расширилась, но происходит далеко не во всех, даже в ведущих. В библиотеках зарубежных университетов появились устойчивые формы работы с учеными.

Группирование всех услуг по направлениям и их сопоставление по библиотекам отечественных и зарубежных университетов позволили выявить сходство и основные различия в поддержке научных исследований:

- в отечественных университетах - обращение к конкретной группе пользователей (авторы, исследователи); в зарубежных - обращение к группе пользователей, занятых определенным видом деятельности;

- общенаучные услуги в обоих случаях являются «продолжением» информационных услуг и связаны с различными аспектами подачи и обработки информации;

- в отечественных университетах нет специального повторения информационно-библиотечных услуг для ученых и специалистов, в зарубежных - есть (повторяется практически вся информация по ресурсам, доступу к ним, особенностям поиска);

- в обоих случаях заранее предлагается ряд материалов, которые могут быть полезны исследователям, причем наборы материалов пересекаются только частично;

- общенаучные услуги пересекаются в части работы над публикацией и наукометрической информацией;

- в зарубежных университетах большое внимание уделяется работе с данными и консультированию, в отечественных - услуги по работе с данными нет вообще.

\section{Обсуждение результатов}

Несомненно, библиотеки отечественных исследовательских университетов уже развили навыки поддержки преподавания и обучения и продемонстрировали свою ценность в этой области, в то время как в сфере поддержки научных исследований библиотекари все еще должны зарекомендовать себя как эффективные и квалифицированные сотрудники. Возможно, что одна из причин - определенная отдаленность иссле- 


\section{Соотношение видов информационно-библиотечных услуг в отечественных и зарубежных университетах}

\begin{tabular}{|l|c|c|}
\hline \multirow{1}{*}{ Виды информационно-библиотечных услуг } & \multicolumn{2}{|c|}{ Библиотеки университетов ${ }^{\text {a }}$} \\
\cline { 2 - 3 } & отечественных & зарубежных \\
\hline $\begin{array}{l}\text { Доступ к базам данных (БД), электронному каталогу, } \\
\text { электронным журналам }\end{array}$ & 3 & 9 \\
\hline $\begin{array}{l}\text { Материалы семинаров, конференций, тренингов } \\
\text { для авторов (презентации) }\end{array}$ & 1 & 9 \\
\hline Лекции для аспирантов (презентации) & 1 & - \\
\hline $\begin{array}{l}\text { Подборки официальных и регламентирующих } \\
\text { документов }\end{array}$ & 2 & 9 \\
\hline Навигаторы и указатели ресурсов и сервисов & 3 & 9 \\
\hline Оказание справочных услуг & 3 & 8 \\
\hline Создание ресурсов на основе материалов университета & - & - \\
\hline Электронные рассылки & 1 & 9 \\
\hline
\end{tabular}

a Прочерк означает отсутствие данных.

\section{Соотношение видов общенаучных услуг в отечественных и зарубежных университетах}

\begin{tabular}{|c|c|c|}
\hline \multirow{2}{*}{ Виды общенаучных услуг } & \multicolumn{2}{|c|}{ Библиотеки университетов а } \\
\hline & отечественных & зарубежных \\
\hline $\begin{array}{l}\text { Помощь в работе с наукометрическими БД: консультации для } \\
\text { авторов по наукометрическим показателям и работе с БД (ин- } \\
\text { дексы, системы и БД цитирования), описание сервисов, ин- } \\
\text { струкции, ведение БД публикаций авторов в БД WoS и Scopus }\end{array}$ & 4 & 9 \\
\hline $\begin{array}{l}\text { Помощь в подготовке публикации: списки рецензируемых } \\
\text { журналов, сопровождение процесса публикаций статей авто- } \\
\text { ра (поддержка публикационной активности) и процесса пу- } \\
\text { бликаций трудов конференций; помощь в написании, оформ- } \\
\text { лении и публикации; организация семинаров, конференций, } \\
\text { тренингов для авторов; работа с системами антиплагиата; } \\
\text { списки журналов ВАК; лингвистическая поддержка }\end{array}$ & 5 & 9 \\
\hline $\begin{array}{l}\text { Помощь в использовании инструментов для научных комму- } \\
\text { никаций: библиографические менеджеры, ссылки на научные } \\
\text { социальные сети (LinkedIn, Mendeley и др.) }\end{array}$ & 3 & 8 \\
\hline Помощь в работе с исследовательскими данными & - & 8 \\
\hline
\end{tabular}

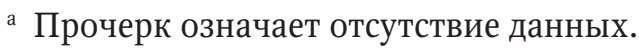


дователей от библиотек. B RIN сообщалось, что преподавательское сообщество рассматривает библиотеку как партнера, научное же сообщество стремится делать «все само» [6]. Это, как предполагалось, может означать, что современные исследователи не ценят библиотеку. И библиотекарям предстоит большая работа, чтобы зарекомендовать себя в качестве квалифицированных сотрудников по поддержке научных исследований. Устойчивые направления деятельности библиотек зарубежных университетов свидетельствуют: библиотеки решили эту задачу.

Наиболее продвинутые библиотеки зарубежных университетов стали использовать функциональные группы, т. е. группы, специально предназначенные для поддержки научных исследований, поддержки преподавания и обучения, а не факультетские (предметные) [7; 11]. Об этом свидетельствует, например, сложившаяся практика библиотек ряда университетов Австралии $[12 ; 13]$. Библиотеки отечественных университетов скорее частично реорганизовали свою деятельность, выделив обслуживание ученых, а некоторые - вообще не выделили их в отдельную группу пользователей. Справедливости ради отметим, что для большинства библиотек зарубежных университетов характерна «двойная» структура, где одни библиотекари решают предметные (факультетские) задачи, а другие - функциональные. Такая структура заменила наиболее распространенную модель - «гибридную» структуру (где есть библиотекари, решающие как предметные, так и функциональные задачи). При этом, как они сами считают, новые обязанности продолжают добавляться к старым задачам, а все старые обязанности сохраняются [14].

Итак, услуги для поддержки научных исследований были разделены авторами на две группы: информационно-библиотечные и общенаучные. К последним отнесены услуги, связанные с опубликованием результатов, их продвижением, хранением и обработкой исходных данных, наукометрическим анализом публикационной активности и т. д. Причем эти услуги или информация о них (фактически повышение информационной грамотности) могут быть оказаны либо индивидуально, либо в рамках специальных обучающих семинаров или рабочих совещаний, либо путем предоставления информации на сайте.

Суммируем отечественный и зарубежный опыт - ту практику, которую можно взять на вооружение уже сегодня для оказания общенаучных услуг. Здесь можно выделить пять основных на- правлений и шестое - комплексное, фактически включающее элементы всех направлений (табл. 5).

Что же касается библиотечно-информационной поддержки научных исследований, то в библиотеках отечественных университетов, как уже было сказано, специально для ученых и исследователей в большинстве случаев она не выделена.

Назовем основные направления библиотечно-информационной поддержки, практикуемые в зарубежных университетах:

- работа с ресурсами (доступ к удаленным и локальным ресурсам различного рода, типа, формата; помощь в поиске необходимых ресурсов - навигация по ресурсам и сайтам; помощь и консультации в работе с определенным ресурсом, тематический поиск литературы);

- справочные услуги;

- работа с выставками: подготовка, организация доступа;

- услуги межбиблиотечного абонемента;

- услуги по приобретению книг;

- услуги сканирования, электронные рассылки.

Итак, сравнительный анализ услуг по поддержке научных исследований 2017 и 2020 гг. показал, что библиотеки университетов нашли устойчивые, необходимые для ученых направления и формы работы с ними. Единственное существенное различие заключается в том, что библиотеки отечественных университетов практически не предлагают услуг по управлению данными. Очевидно, что причина заключается в том, что финансирующие науку структуры пока не требуют от отечественных ученых предоставления дорожной карты по размещению и предоставлению данных, полученных в ходе исследования. Можно быть уверенными, что как только это требование будет сформулировано, научные библиотеки и вузов, и НИИ ее будут оказывать.

Основной вектор развития нацелен на то, чтобы библиотекарь стал равноправным партнером в выполнении исследовательских, преподавательских и учебных задач [15]. Пока в нашей стране это проявляется в расширении персональных консультаций по различным аспектам, связанным с научным исследованием.

Естественно, что библиотека должна развиваться в соответствии с контекстом конкретного университета и института, одинаково у всех быть не может. Для библиотек зарубежных университетов важно, чтобы они более точно отражали миссию учебного заведения и их структура была соответствующим образом перестроена. Этим 


\section{Общенаучные услуги: основные направления}

\section{1. Подготовка и ведение специальных ресурсов, априори полезных исследователям для получения информации, необходимой для проведения, продвижения и организации научных исследований}

Ведение перечня рекомендуемых исследовательских тематических ресурсов.

Новостная лента, содержащая постоянно обновляемые данные из БД Scopus и показывающая 20 наиболее цитируемых и 20 самых свежих статей авторов.

Ведение БД публикаций авторов в БД WoS и Scopus.

Ведение раздела на сайте «Основные определения и понятия».

Предоставление литературы по наукометрии (материалы, касающиеся библиометрической оценки научных исследований, манифесты, руководства).

Предоставление списка ГОСТов по научно-исследовательской работе (например, как помощь в подготовке публикации).

Ведение на сайте специальных информационных текстов, рекомендаций и советов (например, этические принципы при проведении научно-исследовательских работ и публикации результатов; жизненный цикл научной статьи; зачем и как публиковать научные статьи в иностранных журналах; руководство молодому ученому по построению научной карьеры и руководства по использованию информационной техники, руководства «Как читать ссылки», по стилям; подготовка диссертации; что такое плагиат и как его избежать; что такое интеллектуальная собственность; о научном книгоиздании; как начать исследование; советы по подготовке, написанию публикации, продвижению и мониторингу научных статей, любых научных текстов (в том числе докладов); как написать хорошую исследовательскую статью; информация о том, что такое «открытая наука», «открытый доступ», о требованиях фондов по предоставлению данных, об авторском праве.

Ведение ссылок на полезные сайты: конференции НЭИКОН, библиографические менеджеры, «В помощь аспирантам», ВАК, справочник УДК, официальные документы в образовании, системы персональной идентификации ученых, созданные для верификации авторства публикаций в базах данных цитирования; научные социальные сети; аналитические инструменты (SciVal, InCites, Essential Science Indicators, система «Антиплагиат»); портал цифровых карт и географических данных.

Ведение репозиториев и депозиториев с работами авторов организации.

\section{2. Помощь в подготовке публикации}

Подготовка списков рецензируемых журналов, списки журналов ВАК, индексируемых в Scopus и Web of Science.

Помощь в публикации статей автора.

Помощь в публикации трудов конференций, проводимых организацией.

Помощь в написании, оформлении списков литературы.

Справки и консультации по работе с библиографическими менеджерами, по оформлению научноисследовательских работ и редактированию списков к научным работам; устные и в виде рабочих совещаний по предоставлению рекомендаций авторам научных публикаций.

Размещение ссылок на сайте, например, на специальный издательский сервис Oxford Language Editing для авторов научных публикаций, не являющихся носителями английского языка.

Помощь в размещении статей в журналах.

Справки и работа с системами антиплагиата.

Материалы и групповые консультации по академическому письму.

Организация семинаров, конференций, тренингов для авторов.

Консультации по вопросам авторского права, открытого доступа, научного книгоиздания. 


\section{3. Помощь в использовании инструментов для научных коммуникаций}

Консультирование и информирование о библиографических менеджерах.

Ссылки на научные социальные сети, способы оформления ссылок на текст в социальных сетях и на интернет-источник.

Информация и обучение работе с инструментами по предоставлению и обработке информации.

Помощь в создании визуализации.

Помощь в установлении связи (например, с кампусом).

Информация о расписании семинаров по работе с информацией и инструментами для ее обработки.

Помощь по работе с инструментами для цитирования и управления содержанием.

Обучение и помощь в работе с библиографическими менеджерами.

Помощь в работе с инструментами для получения и рассылки информации.

Консультации по вопросам использования компьютерных технологий для исследования.

\section{4. Помощь в работе с исследовательскими данными}

Обучение работе с научными данными, консультирование по вопросам сохранения исследовательских данных.

Архивирование результатов исследований.

Приобретение и лицензирование данных.

Помощь в создании данных и их коллекций.

Хранение и помощь во взаимоиспользовании данных.

Обеспечение безопасности и сохранности, распространение данных.

Размещение данных, статей и других материалов в цифровом репозитории для долгосрочного доступа.

\section{5. Помощь в работе с наукометрическими данными}

Определение публикационной активности и различных персональных научных идентификаторов.

Консультирование для авторов по наукометрическим показателям и работе с наукометрическими БД.

Консультирование по системам регистрации авторов, созданию авторских профилей, работе с аналитическими инструментами.

Ссылки на вебинары.

Помощь в определении и получении авторских идентификаторов и ORCID.

\section{6. Комплексная поддержка научных исследований}

Персональное консультирование по всем вопросам научного исследования; генерирование, курирование и трансформация исследования; работа с ресурсами организации.

Помощь в подготовке обзоров.

Услуги при проведении эмпирических исследований (дизайн исследования, сбор и анализ данных, процесс опубликования, доступ и использование внешних ресурсов).

Курирование: помощь в подборе ресурсов по теме, проведение рабочих совещаний, услуги по цитированию (библиографическим менеджерам, информация о плагиате и о том, зачем нужны ссылки), работа с данными (консультации и помощь в управлении данными, ссылки на репозитории данных).

Организация и проведение рабочих совещаний и семинаров, консультаций со специалистом.

Консультирование по цифровым гуманитарным наукам. 
можно объяснить частичные изменения в описании предоставляемых услуг библиотеками отечественных университетов. Если же эксплицировать вопросы миссии на научные библиотеки НИИ, то основным вопросом остается уровень использования различных форм и методов предоставления услуг.

В целом развитие поддержки научных исследований является сейчас ключевым вопросом для всех библиотек университетов, нацелены ли они только на обучение или на обучение и научно-исследовательскую работу.

И, наконец, авторы хотели бы обратить внимание на появление в библиотечной деятельности такого вида услуги на сайтах библиотек отечественных и зарубежных университетов, как помощь. Предлагаем рассмотреть ее в парадигме «помощь - консультирование сопровождение», отражающей компетентностный уровень библиотекаря.

\section{Примечание}

1 Статус национального исследовательского университета присваивается на конкурсной основе согласно указу Президента Российской Федерации от 7 октября 2008 г. № 1448 «О реализации пилотного проекта по созданию национальных исследовательских университетов». Вне конкурса статус присвоен Национальному исследовательскому ядерному университету «МИФИ» и Национальному исследовательскому технологическому университету «МИСиС». В 2009 г. в открытом конкурсе были определены 12 университетов, получивших статус, в феврале 2010 г. - еще 15 вузов.

\section{Список источников}

1. Лаврик О.Л., Калюжная Т.А., Плешакова М.А. Библиотека и вуз: опыт поддержки научных исследований // Библиотековедение. 2017. Т. 66, № 6. C. $643-650$. DOI: $10.25281 / 0869-608 \mathrm{X}-$ 2017-66-6-643-650.

2. Tibor K. Are You Ready? Tasks and Roles for Academic Libraries in Supporting Research 2.0 // New Library World. 2016. Vol. 117, № 1/2. P. 94104. DOI: 10.1108/NLW-09-2015-0062.

3. Suiter A.M., Moulaison H.L. Supporting Scholars: An Analysis of Academic Library Websites' Documentation on Metrics and Impact // The Journal of Academic Librarianship. 2015. Vol. 41, № 6. P. 814-820. DOI: 10.1016/j.acalib.2015.09.004.

4. Costello L. Survey of Canadian Academic Librarians Outlines Integration of Traditional and Emerging
Services // Evidence Based Library and Information Practice. 2020. Vol. 15, № 3. P. 184-186. DOI: 10.18438/eblip29789.

5. Лаврик О.Л. Особенности научных исследований в библиотеках разного статуса // Труды ГПНТБ CO PAH. 2016. № 10. C. 6-17.

6. Researchers' Use of Academic Libraries and their Services : A Report Commissioned by the Research Information Network and the Consortium of Research Libraries / Research Information Network. 2007 [Электронный ресурc]. URL: https://eprints. soton.ac.uk/263868/1/libraries-report-2007.pdf (дата обращения: 23.03.2020).

7. Morriello R. Birth and Development of Data Librarianship // Italian Journal of Library, Archives, and Information Science. 2020. Vol. 11, № 3. P. 1-15. DOI: $10.4403 /$ jlis.it-12653.

8. Bains S. Manchester's New Order: Transforming the Academic Library Support Model [Электронный реcypc] // Research Libraries UK (RLUK). URL:http:// www.rluk.ac.uk/news/manchestersneworder/ (дата обращения: 23.03.2020).

9. Thomas A., Martin E.R. Developing a Community of Practice: Building the Research Data Management Librarian Academy // Medical Reference Services Quarterly. 2020. Vol. 39, № 4. P. 323-333. DOI: 10.1080/02763869.2020.1826185.

10. Ведущие российские университеты [Электронный ресурс] // Национальный исследовательский университет «Высшая школа экономики». URL: https:// strategy.hse.ru/niu (дата обращения: 23.03.2020).

11. Jaguszewski J.M., Williams K. New Roles for New Times: Transforming Liaison Roles in Research Libraries. Washington : ARL, 2013 [Электронный pecypc]. URL: https://www.arl.org/wp-content/ uploads/2015/12/nrnt-liaison-roles-revised.pdf (дата обращения: 23.03.2020).

12. Bains $S$. Teaching "Old” Librarians New Tricks // SCONUL Focus. 2013. № 58. P. 8-11.

13. Doskatsch I. Perceptions and Perplexities of the Faculty Librarian Partnership: An Australian Perspective // Reference Services Review. 2003. Vol. 31, № 2. P. 111-121. DOI: 10.1108/00907320310476585.

14. Rodwell J., Fairburn L. Dangerous Liaisons? Defining the Faculty Liaison Librarians Service Model, Its Effectiveness and Sustainability // Library Management. 2008. Vol. 29, № 1/2. P. 116-124. DOI: $10.1108 / 01435120810844694$.

15. Cain T.J., Cheek F.M., Kupsco J. et al. Health Sciences Libraries Forecasting Information Service Trends for Researchers: Models Applicable to All Academic Libraries // College and Research Libraries. 2016. Vol. 77, № 5. P. 595-613. DOI: 10.5860/ crl.77.5.595. 


\title{
Support of Scientific Research as Libraries' Field of Activity
}

\author{
Olga L. Lavrik ${ }^{a}$ *, Tatyana A. Kalyuzhnaya ${ }^{\mathrm{b} * *}$, \\ State Public Scientific Technological Library of the Siberian Branch of the Russian Academy of Sciences, \\ 15 Voskhod Str., Novosibirsk, 630102, Russia \\ a ORCID 0000-0001-8859-8921; SPIN 8304-3655 \\ b ORCID 0000-0001-8637-2793; SPIN 5315-0638 \\ E-mail:* Lavrik@spsl.nsc.ru, ${ }^{* *}$ Kalyuzhnaya@spsl.nsc.ru
}

\begin{abstract}
Support of scientific research as a field of activity is one of the leading topics discussed in the professional library, especially foreign, periodicals. In 2020, there was conducted the analysis of research support services provided by research libraries of domestic and foreign universities. Based on the experience of the 2017' study, the authors divided all research support services into two groups for the analysis of 2020: information and library services and general scientific services. Information and library services include all those that the library traditionally provides to its readers and users, taking into account the development of modern information technologies. General scientific services are essentially a certain continuation of the work with information that researchers have already received in the course of their work. For the analysis of research universities, the authors selected Russian universities that were included in the Shanghai ranking of world universities for 2020 (there are nine of them), followed by the same number of foreign universities. Comparison of the results of the 2017' and 2020' studies showed that university libraries have found stable, relevant directions and forms of communication with scientists. They can be grouped as follows: preparation and maintenance of special resources that are a priori useful to researchers for obtaining information necessary for conducting, promoting and organizing scientific research; assistance in preparing publications; assistance in using tools for scientific communication; assistance in working with research data; assistance in working with scientometric data; comprehensive support for scientific research. The article indicates that the core of this area of library and information activity has been formed over the past four years. The only significant difference in the activities of research libraries of foreign and domestic universities is that the latter do not offer data management services. The authors draw attention to the appearance in library activities of such type of services as "help"/assistance on the websites of libraries of domestic and foreign universities. The authors propose to consider it in the "help - consulting - support" paradigm, which reflects the competence level of the librarian.
\end{abstract}

Key words: organization of librarianship, research libraries, support of scientific research, universities, fields of library and information activity, services for information support of research, services for general scientific support of research.

Citation: Lavrik O.L., Kalyuzhnaya T.A. Support of Scientific Research as Libraries' Field of Activity, Bibliotekovedenie [Russian Journal of Library Science], 2020, vol. 69, no. 6, pp. 567-579. DOI: 10.25281/0869-608X-2020-69-6-567-579.

Acknowledgements. The research work was performed as part of the state task of the State Public Scientific Technological Library of the Siberian Branch of the Russian Academy of Sciences (SPSTL SB RAS) (Project 0334-2019-0001).

\section{References}

1. Lavrik O.L., Kalyuzhnaya T.A., Pleshakova M.A. Library and its University: The Experience of Research Support, Bibliotekovedenie [Russian Journal of Library Science], 2017, vol. 66, no. 6, pp. 643-650.
DOI: 10.25281/0869-608X-2017-66-6-643-650 (in Russ.).

2. Tibor K. Are You Ready? Tasks and Roles for Academic Libraries in Supporting Research 2.0, New 
Library World, 2016, vol. 117, no. 1/2, pp. 94-104. DOI: 10.1108/NLW-09-2015-0062.

3. Suiter A.M., Moulaison H.L. Supporting Scholars: An Analysis of Academic Library Websites' Documentation on Metrics and Impact, The Journal of Academic Librarianship, 2015, vol. 41, no. 6, pp. 814-820. DOI: 10.1016/j.acalib.2015.09.004.

4. Costello L. Survey of Canadian Academic Librarians Outlines Integration of Traditional and Emerging Services, Evidence Based Library and Information Practice, 2020, vol. 15, no. 3, pp. 184-186. DOI: 10.18438/eblip29789.

5. Lavrik O.L. The Features of Scientific Researches in Libraries of Different Status, Trudy GPNTB SO RAN [Proceedings of the State Public Scientific and Technological Library of the Siberian Branch of the Russian Academy of Sciences], 2016, no. 10, pp. 6-17 (in Russ.).

6. Researchers' Use of Academic Libraries and their Services: A Report Commissioned by the Research Information Network and the Consortium of Research Libraries, Research Information Network, 2007. Available at: https://eprints.soton. ac.uk/263868/1/libraries-report-2007.pdf (accessed 23.03.2020).

7. Morriello R. Birth and Development of Data Librarianship, Italian Journal of Library, Archives, and Information Science, 2020, vol. 11, no. 3, pp. 1-15. DOI: $10.4403 /$ jlis.it-12653.

8. Bains S. Manchester's New Order: Transforming the Academic Library Support Model, Research Libraries UK (RLUK). Available at: http://www. rluk.ac.uk/news/manchestersneworder/ (accessed 23.03.2020).
9. Thomas A., Martin E.R. Developing a Community of Practice: Building the Research Data Management Librarian Academy, Medical Reference Services Quarterly, 2020, vol. 39, no. 4, pp. 323-333. DOI: $10.1080 / 02763869.2020 .1826185$.

10. Leading Russian Universities, Natsional'nyi issledovatel'skii universitet "Vysshaya shkola ekonomi$k i$ " [National Research University "Higher School of Economics"]. Available at: https://strategy.hse.ru/ niu (accessed 23.03.2020) (in Russ.).

11. Jaguszewski J.M., Williams K. New Roles for New Times: Transforming Liaison Roles in Research Libraries. Washington, ARL Publ., 2013. Available at: https://www.arl.org/wp-content/uploads/2015/12/nrnt-liaison-roles-revised.pdf (accessed 23.03.2020).

12. Bains S. Teaching "Old” Librarians New Tricks, SCONUL Focus, 2013, no. 58, pp. 8-11.

13. Doskatsch I. Perceptions and Perplexities of the Faculty Librarian Partnership: An Australian Perspective, Reference Services Review, 2003, vol. 31, no. 2, pp. 111-121. DOI: 10.1108/00907320310476585.

14. Rodwell J., Fairburn L. Dangerous Liaisons? Defining the Faculty Liaison Librarians Service Model, Its Effectiveness and Sustainability, Library Management, 2008, vol. 29 , no. $1 / 2$, pp. $116-124$. DOI: 10.1108/01435120810844694.

15. Cain T.J., Cheek F.M., Kupsco J. et al. Health Sciences Libraries Forecasting Information Service Trends for Researchers: Models Applicable to All Academic Libraries, College and Research Libraries, 2016, vol. 77, no. 5, pp. 595-613. DOI: $10.5860 /$ crl.77.5.595. 